\title{
Development of a self-scan to evaluate and improve person-centered care in nursing homes: A Delphi study
}

\author{
Irene J.M. Muller-Schoof, Annerieke Stoop, Marjolein E.A. Verbiest, Katrien G. Luijkx \\ Tranzo, Scientific Center for Care and Wellbeing, Tilburg School of Social and Behavioral Sciences, Tilburg University, The \\ Netherlands
}

Received: December 24, 2021

Accepted: January 20, 2022

Online Published: January 28, 2022

DOI: $10.5430 /$ jnep.v12n6p22

URL: https://doi.org/10.5430/jnep.v12n6p22

\begin{abstract}
Background and objective: Person centered care (PCC) has become the gold standard for providing care in nursing homes (NHs). Therefore, it is important for healthcare professionals in NHs to learn PCC-skills and to be supported to learn about- and improve the quality of PCC they provide. At this moment an instrument to support healthcare professionals in NHs to monitor and evaluate PCC is limited. The aim of the study was to develop a self-evaluation tool that provides healthcare professionals in NHs insight into the extent to which they provide PCC to residents, so that they can learn and further improve their current ways of working in a person-centered way.

Methods: A three-round Delphi study with an expert panel $(n=25)$ in the domains of PCC, quality of NH care and education of caring staff. Findings were validated by residents and relatives during semi-structured interviews. Thematic analysis and descriptive statistics were used to analyze the data.

Results: In the first round the experts did not provide measuring instruments, but we identified 18 key aspects of PCC. In the second round, three clusters were identified, and a scale was added, to enable assessment. In the third round, we deduplicated, restructured and used more clear language. This led to 14 key aspects of PCC, 24 measures, grouped into five clusters: knowing the resident, establishing relationship, a respectful approach, making decisions jointly and personal development. The result is a PCC self-scan for healthcare professionals in NHs. Residents and relatives, agreed with all aspects and stated that no aspects were missing.

Conclusions: In this study we developed an accessible self-report learning tool for healthcare professionals that makes it possible to evaluate and improve their PCC-skills and improve the quality of PCC in NHs.
\end{abstract}

Key Words: Delphi, Person-centered care, Nursing homes, Learning, Quality of care

\section{BACKGROUND}

Quality improvement of nursing home $(\mathrm{NH})$ care has been a challenge for years. ${ }^{[1-3]}$ Nowadays, person-centered care (PCC) is accepted as the gold standard in long-term care for older adults. ${ }^{[4,5]} \mathrm{PCC}$ is a comprehensive approach to care that takes into account the whole person and is underpinned by values of respect for personhood, the individual right to self-determination, mutual respect, and understanding. ${ }^{[5,6]}$ To ensure high-quality PCC, (student) healthcare professionals (hereafter, healthcare professionals) in NHs have to keep up with fast-paced developments and constantly continue to learn and improve their PCC-giving practices.

One way to assess the quality of PCC is with instruments or tools healthcare professionals use to rate the extent to which

*Correspondence: Irene J.M. Muller-Schoof; Email: i.j.m.muller-schoof@tilburguniversity.edu; Address: Tranzo, Scientific Center for Care and Wellbeing, Tilburg School of Social and Behavioral Sciences, Tilburg University, The Netherlands. 
$\mathrm{NH}$-care is person-centered. ${ }^{[7-10]}$ An example is the PersonCentered Care Assessment Tool (P-CAT), a self-report assessment scale that measures the extent to which $\mathrm{NH}$ teams rate their wards to be person-centered. ${ }^{[11]}$ However, none of the existing tools cover all aspects of PCC in NHs, such as tools assessing compassion and dignity, ${ }^{[7,12]}$ client experiences $(\mathrm{CQ} \text {-index })^{[7,13]}$ or person-centered communication, ${ }^{[7,14,15]}$ nor do they enable healthcare professionals to evaluate their own PCC-giving practices. ${ }^{[7-11,16,17]}$ Accordingly, there is a need for a tool that healthcare professionals in NHs can use to evaluate and improve all aspects of their PCC-giving practices. Because more administration leads to more time pressure, resulting in less time to provide PCC, such a tool should not increase the administrative burden experienced by healthcare professionals in NHs. ${ }^{[18,19]}$ The perspectives of $\mathrm{NH}$ residents and their relatives should also be incorporated in the development of a quality improvement tool to ensure the tool meets their needs and desires and, therefore, aligns with PCC. ${ }^{[20,21]}$

Previous research has shown that actively involving practically trained caregivers in their own learning activities and keeping them responsible for their own learning are important factors in facilitating learning (Muller-Schoof, 2021). Practically trained caregivers make up $80 \%$ of the healthcare professionals in NHs in Western society. ${ }^{[22-25]}$ Therefore, we aimed to develop a self-evaluation tool that helps healthcare professionals to reflect on PCC aspects and discuss these aspects with others, such as team leaders, colleagues, or residents, as part of a dynamic learning process. The tool was intended to actively involve healthcare professionals in their own learning process.

\section{METHOD}

This study was part of a larger project ${ }^{[26]}$ that aims to develop learning strategies to transfer scientific knowledge regarding PCC into tools and instruments for healthcare professionals who work in daily practice in NHs. As part of the learning strategies, we aimed to develop a tool that enables healthcare professionals to evaluate and improve their own PCC. Our research question was: Which tool provides healthcare professionals in NHs insight into the extent to which they provide PCC, so that they can learn and improve in PCC without additional care registrations?

\subsection{Study design}

A Delphi method was employed to develop a tool that enables healthcare professionals in NHs to evaluate and improve their PCC-giving skills. The Delphi method focuses on consensusbuilding by using a series of questionnaires to collect data from a panel. ${ }^{[27]}$ We also conducted semi-structured inter- views with $\mathrm{NH}$ residents and relatives to validate the findings of the Delphi study.

\subsection{Delphi study}

A Delphi study was conducted between March and May 2020. We invited 52 people from our networks (author 1, 2 and 4) to participate in the study. These participants had expertise in the domains of quality of care in NHs, PCC, nursing education (at both practical and applied science institutions) and the practice of $\mathrm{NH}$ care (some participants were nurses, both practically trained and educated at the university of applied sciences). We aimed for an evenly distribution across the expert domains, with a total of 15-20 experts and a minimum of three to four experts per domain. We recruited participants by sending an e-mail in which we explained the purpose of our study, the expert domains included, and the expected time investment. We also left room for questions. When experts agreed to participate, we sent an information letter and a link to the questionnaire by e-mail. We made use of Qualtrics, which is a platform for creating and distributing web-based surveys. All experts provided electronic informed consent in the first questionnaire. The responses to the questionnaires were analyzed and summarized by three authors (author 1,2 and 4) and fed back anonymously to the expert panel. All experts were asked to participate in each round. Each questionnaire could be completed by the experts within a two-week period. In case of non-response, we sent an e-mail reminder after one week and a second reminder after two weeks.

Originally, we planned three rounds: an inventory round, a prioritization round, and a consensus round (see Figure 1). In the inventory round, we introduced the subject of the study and asked experts if they knew any tools or instrument aimed at healthcare professionals in $\mathrm{NHs}$, in order to evaluate whether the care they provided was person-centered. Originally, we aimed to make an inventory of all measures, instruments, quality indicators, and feedback mechanisms that experts would come up with; ask them to prioritize the measures in the second round; and reach consensus on the most important measure in the third round (see Figure 1).

However, because experts did not come up with tools to evaluate PCC in the first round (only with ways to provide PCC) we decided to change our focus for the second round (see Figure 1). First, we analyzed the input of the experts provided in the first round and categorized this into aspects of PCC. We reasoned that a set of indicators linked to these aspects could possibly be the answer to our research question.

Therefore, we asked the experts in the second round to prioritize the identified aspects of PCC, rank their top three 
most important ones, and argue their choice. We also asked the experts how to measure their top three aspects of PCC. Based on the outcome of round two, we clustered all PCC aspects and listed the most important ones as ranked by the experts, supplemented with measures. To turn this list into an evaluation and improvement tool to learn from, we added a scale for self-assessment. In the third round, we shared the tool with the experts. We asked the experts: "Which of the following aspects of PCC do you think does NOT fit in the tool for providing PCC?" We also asked if the language was appropriate for all healthcare professionals in NHs or if aspects were missing. If they were missing, we asked if the experts had any suggestions. Furthermore, we asked whether the experts found that this tool would support healthcare professionals in reflecting on the extent to which they provide PCC. With the input of the experts, we adjusted the PCC tool, which we called the PCC self-scan. Afterwards, we presented the adjusted PCC self-scan from round three to the experts.

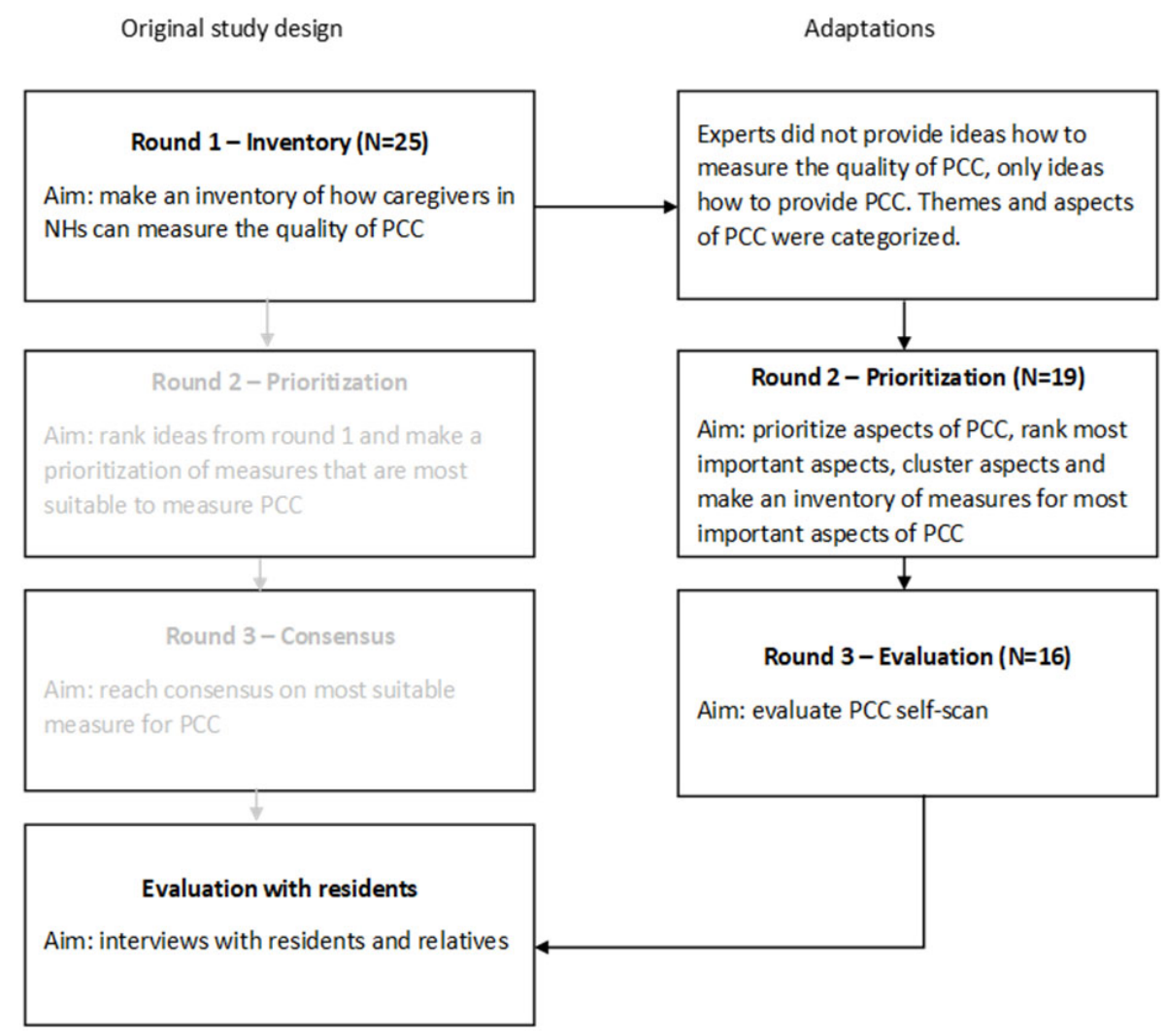

Figure 1. Flow of the study

\subsection{Interviews with residents and relatives}

To validate the findings of the Delphi study and include the perspectives of residents and their relatives, we conducted interviews between July and September 2020. We aimed to recruit five participants. Recruitment was organized by a nurse within a collaborating $\mathrm{NH}$ connected to the larger research project. Inclusion criteria were that participants were cognitively competent to give written consent for participation and to be interviewed by telephone. We used a purposive sampling technique in which the nurse determined which residents were suitable, informed them orally and via an information letter about the study aim and procedures, supported residents in signing the consent form and made an appointment for a date and time at which the researcher could call them. We conducted semi-structured interviews of approximately 30 minutes. During the interviews, the aim of the study was explained, as were the purpose of the PCC self-scan, how it was developed, and which aspects of PCC were covered in the self-scan. Residents and relatives were asked how important these aspects were and if any aspects were missing.

\subsection{Data analysis}

The answers to the open-ended questions in the Delphi study were analyzed and categorized into different aspects of PCC by authors 1,2 , and 4 .

Based on the answers from the second round we used a scoring system to further prioritize the aspects of PCC. As experts 
provided their top three PCC aspects, we assigned their first choices three points, their second choices two points, and their third choices one point. All scores were added up, and the total scores were used to prioritize the key aspects of PCC. We also listed the measures to cover all prioritized aspects of PCC, as provided by the experts. As experts pointed out overlap in aspects and measures that were multifaceted, we processed the feedback by clustering the aspects and removing duplicates. Altogether, this resulted in a tool for healthcare professionals to self-assess their PCC competence, which will be further described in the Results section.

In addition, the first author analyzed the audio recordings of the semi-structured interviews with residents and relatives and summarized the answers.

\subsection{Ethics statement}

This study was approved by the Ethical Review Board of the Tilburg School of Social and Behavioral Sciences of Tilburg University (registration number RP60 and amendment RP60).

\section{RESULTS}

\subsection{Participants in the Delphi study}

Of the 52 invited experts, 25 agreed to participate by responding to the first questionnaire. Six participants withdrew after the first round of the Delphi study due to other priorities related to their work in $\mathrm{NH}$ care and care education because of the COVID-19 lockdown in March 2020. Table 1 shows the distribution over the expert domains per round. We reached our minimum number of 15 experts and three to four experts per domain in each round. Practically trained caregivers were in both the domain of practice and that of education in all rounds.

Table 1. Number of experts and expert areas represented per round

\begin{tabular}{llll}
\hline & $\begin{array}{l}\text { Round 1 } \\
(\mathbf{N})\end{array}$ & $\begin{array}{l}\text { Round 2 } \\
(\mathbf{N})\end{array}$ & $\begin{array}{l}\text { Round 3 } \\
(\mathbf{N})\end{array}$ \\
\hline Quality NH & 13 & 8 & 9 \\
Practice NH & 8 & 7 & 6 \\
PCC & 11 & 7 & 8 \\
Education & 14 & 8 & 8 \\
Total N & 25 & 19 & 16 \\
\hline
\end{tabular}

Note. $\mathrm{NH}=$ nursing home, $\mathrm{PCC}=$ person-centered care

\subsection{Delphi rounds}

\subsubsection{First round}

Based on experts' input, we found 18 key aspects of PCC (see Table 2).

Published by Sciedu Press

\subsubsection{Second round}

In the second round, experts prioritized all aspects of PCC that resulted from round one. Table 2 shows the prioritization scores and ranking of these PCC aspects. Experts also argued for their choices and pointed out aspects that overlapped. For instance, they noted that someone uses communication skills by offering tailor-made care (see Table 2, numbers 18 and 4 , respectively). As a result, the 18 aspects of PCC became 14 (see Table 2). Based on this, we clustered all aspects, which led to the following three most important clusters of aspects: (1) providing relational care, including knowing the resident; (2) providing care that leads to the resident's well-being;

(3) knowing yourself as a healthcare professional.

Table 2. Prioritization and clustering of key aspects of PCC

\begin{tabular}{lll}
\hline The healthcare professional & $\begin{array}{l}\text { Total } \\
\text { prioritization } \\
\text { score* }\end{array}$ & Cluster \\
\hline 1. Knows the client & 25 & 1 \\
2. Establishes a reciprocal relationship & 16 & 1 \\
3. Has an attentive attitude to the whole person & 12 & 2 \\
4. Offers tailor-made care & 11 & 2 \\
5. Knows her-/himself & 9 & 3 \\
6. Provides care that leads to well-being of the client & 8 & 2 \\
7. Continuously learns and develops her-/himself & 8 & 3 \\
8. Encourages client autonomy & 7 & 2 \\
9. Uses relational skills & 5 & 1 \\
10. Initiates shared decision-making & 3 & 2 \\
11. Provides care based on a flexible attitude & 3 & 2 \\
12. The environment contributes to client well-being & 2 & 2 \\
13. Provides care based on a curious basic attitude & 2 & 2 \\
14. Provides care based on a sensitive basic attitude & 2 & 2 \\
15. Knows the person-centered healthcare framework & 1 & 2 \\
16. Provides sensitive care & 0 & 2 \\
17. Provides healing care & 0 & 2 \\
18. Uses communication skills & 0 & 1 \\
\hline Note. * Scores are the sum of the prioritization (first choice $=$ three points, second choice \\
= two points, third choice = one point); total score ranging from minimum 0 to maximum 57; \\
1 = cluster 'providing relational care, including knowing the resident'; 2 = cluster \\
'providing care that leads to the resident's well-being'; 3 = cluster \\
'knowing yourself as healthcare professional'. & & \\
& & 2 \\
& & 2 \\
\hline
\end{tabular}

In addition, experts provided input into how to measure their top three aspects of PCC. In total, we received 14 measures to cover all unduplicated aspects of the three clusters of PCC (see Table 3). We also added a 5-point Likert scale, which enables healthcare professionals to assess their current PCCskills. The scale ranged from 1 (= no control or knowledge) to 5 (= excellent control or knowledge). In addition, we rewrote the phrase "establishes a reciprocal relationship" to "providing relational care," as some experts found the word "reciprocal" too complex.

\subsection{Third round}

We asked experts in round three to provide feedback on the preliminary version of the PCC self-scan, and whether this PCC self-scan gave insight into the extent to which healthcare professionals in NHs provide PCC. The majority (75\%, 
$\mathrm{n}=12)$ agreed, $19 \%(\mathrm{n}=3)$ were indecisive and $6 \%(\mathrm{n}=$

1) disagreed. We used most disagreements or indications of "not knowing" to make changes to the final PCC self-scan and to our advice to use it.

Based on experts' feedback, we shortened the sentences and used clear language to make the PCC self-scan accessible for all healthcare professionals, including practically trained caregivers. We also adapted the clusters. First, the cluster "providing relational care, including knowing the resident" was split into "providing relational care" and "knowing the resident." "Knowing the resident" was renamed to "knowing and acknowledging the resident." In addition, we changed the more general cluster "providing care that leads to the resident's well-being" into two more specific clusters: "shared decision making" and "respectful approach." We renamed the cluster "knowing yourself as a healthcare professional" to "feedback and personal development." Furthermore, we included representatives of people with dementia by adding them in several items, such as "I treat their relations (or representative) with respect." Multiple measures of PCC aspects were split into single measures. For instance, the measure "I know the life course, personality traits, relationships/social context of the residents to whom I provide care" was split into three single measures, each addressing a single aspect of PCC ("I know the life course," "I know the personality traits," and "I know the relationships/social context"). We also changed the measure "I prefer to provide care with peace and calm, know when I am not peaceful and calm, and know how to find that again" into a broader self-knowledge measure, namely "I know my own standards and values."

Table 3. Second-round results: preliminary version of the PCC self-scan

\begin{tabular}{|c|c|c|c|c|c|c|c|c|c|}
\hline 1 & 2 & 3 & 4 & \multicolumn{6}{|c|}{5} \\
\hline $\begin{array}{l}\text { No control or } \\
\text { knowledge }\end{array}$ & $\begin{array}{l}\text { Hardly control or } \\
\text { knowledge }\end{array}$ & $\begin{array}{l}\text { Adequate control or } \\
\text { knowledge }\end{array}$ & $\begin{array}{l}\text { Good control or } \\
\text { knowledge }\end{array}$ & \multicolumn{6}{|c|}{$\begin{array}{l}\text { Excellent control } \\
\text { or knowledge }\end{array}$} \\
\hline \multicolumn{4}{|c|}{ Providing relational care, including knowing the resident } & \multicolumn{6}{|c|}{ My score: } \\
\hline \multicolumn{4}{|c|}{ I know the care plans of the residents to whom I provide care } & & & & 3 & 4 & \\
\hline \multicolumn{4}{|c|}{ I know the life course, personality traits, and relationships/social context of the residents to whom I provide care } & & & & 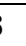 & 4 & \\
\hline \multicolumn{4}{|c|}{$\begin{array}{l}\text { I know what the residents to whom I provide care like to do, what they wish for, what they find important, and } \\
\text { what they dislike }\end{array}$} & & & & & 4 & \\
\hline \multicolumn{4}{|c|}{ I know what each resident still can and wants to do, and do not take over } & & 2 & & 3 & 4 & \\
\hline \multicolumn{4}{|c|}{ I first coordinate with the resident and meet with the resident's needs and/or wishes before providing care } & & 2 & & 3a & 4 & \\
\hline \multicolumn{4}{|c|}{ Providing care that leads to the resident's well-being } & & & & & & \\
\hline \multicolumn{4}{|c|}{ I listen without judgment and do not fill in } & & 2 & & 3 & 4 & \\
\hline \multicolumn{4}{|c|}{ The resident's wish is leading and determines what a day looks like } & & & & 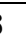 & 4 & \\
\hline \multicolumn{4}{|c|}{ I consult with the resident (or their representative), and we decide together } & & 2 & & 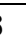 & 4 & \\
\hline \multicolumn{4}{|c|}{ I approach the resident holistically: I know and see the person (not the condition) } & & & & 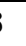 & 4 & \\
\hline \multicolumn{4}{|c|}{$\begin{array}{l}\text { I regularly check whether the resident is still satisfied and whether my care contributes to the resident's } \\
\text { well-being }\end{array}$} & & & & & 4 & \\
\hline \multicolumn{10}{|c|}{ Knowing yourself as a healthcare professional } \\
\hline \multicolumn{4}{|c|}{ I ask myself daily why I care the way I do } & & & & 3 & 4 & \\
\hline \multicolumn{4}{|c|}{ I regularly ask for feedback from residents and colleagues, can receive feedback and do something with it } & & & & 3 & 4 & \\
\hline \multicolumn{4}{|c|}{ I participate in peer review and indicate my points for development to the team } & & & & 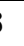 & 4 & \\
\hline \multicolumn{4}{|c|}{$\begin{array}{l}\text { I prefer to provide care with peace and calm, know when I am not peaceful and calm, and know how to find that } \\
\text { again }\end{array}$} & & & & 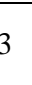 & 4 & \\
\hline
\end{tabular}

Finally, one expert disagreed that this PCC self-scan gave insight into the extent to which healthcare professionals in NHs provide PCC. The expert argued that the PCC self-scan could not be used as a stand-alone tool. We agreed and advise using the PCC self-scan in combination with reflection with others. An expert was indecisive because the self-scan was lacking an interprofessional consulting aspect. We therefore added the measure "I consult with colleagues" to the cluster "shared decision making." The second indecisive expert argued that the relational aspect, such as that in "to really have an eye for the other, to treat someone with respect" was underexposed. Therefore, we renamed the cluster "Providing relational care" to "Aligning, connecting and establishing a relationship," to make the phases of building relations more 
explicit. We added the measure "I treat the residents with PCC self-scan with five clusters of 14 key aspects and 24 respect." One indecisive expert could not see how this PCC measures. The PCC self-scan was originally developed in self-scan would work in practice. Figure 2 shows the final Dutch and translated forward-backward into English.

\section{Self-scan: person-centered care}

What is your assessment of your command of the aspects below? Circle the most suitable answer.

\begin{tabular}{|c|c|c|c|c|c|c|c|c|}
\hline & 1 & 2 & 3 & 4 & \multicolumn{4}{|c|}{5} \\
\hline \multicolumn{2}{|r|}{$\begin{array}{l}\text { Strongly disagree/ } \\
\text { No command }\end{array}$} & $\begin{array}{c}\text { Disagree/ } \\
\text { Inadequate command }\end{array}$ & Neutral & $\begin{array}{l}\text { Agree/ } \\
\text { Adequate command }\end{array}$ & \multicolumn{4}{|c|}{$\begin{array}{l}\text { Strongly agree/ } \\
\text { Excellent command }\end{array}$} \\
\hline & & & & & my & scor & & \\
\hline 1 & $\begin{array}{l}\text { Knowing the res } \\
\text { What I know ab } \\
\text { a. their ca } \\
\text { b. their lif } \\
\text { c. their pe } \\
\text { d. their ne } \\
\text { e. what th } \\
\text { f. what th } \\
\text { g. what th } \\
\text { h. what th } \\
\text { When I provide }\end{array}$ & $\begin{array}{l}\text { the residents to whom } \\
\text { lan } \\
\text { cle } \\
\text { nal characteristics } \\
\text { st and dearest (family a } \\
\text { onsider important } \\
\text { lislike } \\
\text { till like to do } \\
\text { urther wishes are } \\
\text { I see the whole person }\end{array}$ & care: & & $\begin{array}{l}1 \\
1 \\
1 \\
1 \\
1 \\
1 \\
1 \\
1 \\
1\end{array}$ & $\begin{array}{ll}2 & 3 \\
2 & 3 \\
2 & 3 \\
2 & 3 \\
2 & 3 \\
2 & 3 \\
2 & 3 \\
2 & 3 \\
2 & 3\end{array}$ & $\begin{array}{l}4 \\
4 \\
4 \\
4 \\
4 \\
4 \\
4 \\
4 \\
4\end{array}$ & $\begin{array}{l}5 \\
5 \\
5 \\
5 \\
5 \\
5 \\
5 \\
5 \\
5\end{array}$ \\
\hline 2 & $\begin{array}{l}\text { Coordinating, } m \\
\text { a. I first c } \\
\text { providi } \\
\text { b. The car }\end{array}$ & $\begin{array}{l}\text { g contact and establish } \\
\text { linate with the resident } \\
\text { rovide is not a one-way }\end{array}$ & $\begin{array}{l}\text { tionship } \\
\text { et their ne } \\
\text { stablish }\end{array}$ & $\begin{array}{l}\text { wishes before } \\
\text { hip }\end{array}$ & 1 & $\begin{array}{l}23 \\
23\end{array}$ & 4 & $\begin{array}{l}5 \\
5\end{array}$ \\
\hline 3 & $\begin{array}{l}\text { Respectful appr } \\
\text { a. I treat t } \\
\text { b. I treat t } \\
\text { c. I listen } \\
\text { d. I do no }\end{array}$ & $\begin{array}{l}\text { esidents with respect } \\
\text { nearest and dearest (o } \\
\text { out judging } \\
\text { in for someone else }\end{array}$ & tative) w & & $\begin{array}{l}1 \\
1 \\
1 \\
1\end{array}$ & $\begin{array}{ll}2 & 3 \\
2 & 3 \\
2 & 3 \\
2 & 3\end{array}$ & 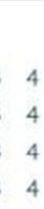 & $\begin{array}{l}5 \\
5 \\
5 \\
5\end{array}$ \\
\hline 4 & $\begin{array}{l}\text { Making decisior } \\
\begin{array}{l}\text { a. I consu } \\
\text { in decis } \\
\text { b. I consu } \\
\text { c. We mal }\end{array}\end{array}$ & $\begin{array}{l}\text { intly } \\
\text { ith the resident/represe } \\
\text {-making, if applicable } \\
\text { ith colleagues } \\
\text { ecisions jointly with the }\end{array}$ & $\begin{array}{l}\text { ad get the } \\
\text { represen }\end{array}$ & and dearest involved & $\begin{array}{l}1 \\
1\end{array}$ & $\begin{array}{l}2 \\
2\end{array}$ & $\begin{array}{l}4 \\
4\end{array}$ & $\begin{array}{l}5 \\
5\end{array}$ \\
\hline 5 & $\begin{array}{l}\text { Feedback and p } \\
\begin{array}{l}\text { a. I check } \\
\text { and sat } \\
\text { b. I regula } \\
\text { c. I regula } \\
\text { d. I do so } \\
\text { e. I take } p \\
\text { f. I know }\end{array}\end{array}$ & $\begin{array}{l}\text { nal development } \\
\text { ularly whether the care } \\
\text { ction } \\
\text { ask the resident's loved } \\
\text { sk colleagues for feedb } \\
\text { hing with the feedback } \\
\text { n intervision } \\
\text { own norms and values }\end{array}$ & $\begin{array}{l}\text { contribut } \\
\text { feedback } \\
\text { five }\end{array}$ & sident's wellbeing & $\begin{array}{l}1 \\
1 \\
1 \\
1 \\
1 \\
1\end{array}$ & $\begin{array}{ll}2 & 3 \\
2 & 3 \\
2 & 3 \\
2 & 3 \\
2 & 3\end{array}$ & 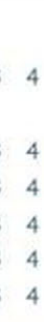 & $\begin{array}{l}5 \\
5 \\
5 \\
5 \\
5\end{array}$ \\
\hline
\end{tabular}

Figure 2. Final version of the PCC self-scan 


\subsection{Interviews with residents and relatives}

In total, two male NH residents (101 and 86 years old) and two relatives, a son and a daughter of persons with dementia, were interviewed. One of the potential interviewees, a female $\mathrm{NH}$ resident, refused the interview at the agreed time. Due to the COVID-19 pandemic and related measures, it was not possible to find a new participant in time. All interviewees agreed that all five clusters of the PCC self-scan were important, and that no aspect was missing. One participant said:

"If healthcare professionals know the residents well and the relation is good, good PCC will follow as a consequence." (relative)

Based on the results of the interviews no further adaptations were made to the PCC self-scan.

\section{Discussion}

In this study, we aimed to answer to following question: which tool provides (student) healthcare professionals in $\mathrm{NHs}$ insight into the extent to which they provide PCC, so that they can learn and improve in PCC, without additional care registrations? Based on results from our Delphi study, we developed a PCC self-scan based on 14 key aspects of PCC, resulting in 24 measures, grouped into five clusters. A 5-point Likert scale enables health professionals to rate their skills level regarding the individual items. The findings of the Delphi study were validated by $\mathrm{NH}$ residents and relatives. According to experts, residents, and relatives, the PCC self-scan is a useful tool for evaluating and improving the quality of PCC in NHs.

To date, no tool has been developed that enables healthcare professionals in NHs to evaluate and improve the quality of their PCC-giving practices. Therefore, this study and the PCC self-scan make a valuable contribution to the current literature regarding ways to assess and improve the quality of PCC. ${ }^{[7-10]}$

Comparing the PCC self-scan with other existing tools that also measure PCC highlights the uniqueness and added value of the self-scan. First, the Person-centered Care Assessment Tool (P-CAT) aims to measure the extent to which staff members who take care of people with dementia rate their wards as person-centered. ${ }^{[11]}$ The PCC self-scan, however, has been developed for healthcare professionals in NHs and not for a ward. In addition, the PCC self-scan can be applied to all $\mathrm{NH}$ care, not exclusively dementia care. Secondly, the Personcentred Practice Inventory - Staff (PCPI-S) examines how hospital nursing staff perceive person-centered practice. ${ }^{[28]}$ This is an extensive list with 59 items, which was tested by registered nurses in eight acute hospital settings, not in NHs.
In the Western society, the vast majority (about $80 \%$ ) of the direct care staff in NHs is practically educated. ${ }^{[22-25]}$ As a result, the PCPI-S has not been tested and/or validated by this majority in an $\mathrm{NH}$ setting at the moment of publication of this study. From an earlier study, ${ }^{[29]}$ we know that learning materials for practically trained caregivers should not be too long, should not contain difficult vocabulary, and should not be incomprehensible. Our PCC self-scan has taken this into account. This does not apply to the PCPI-S.

Finally, we know from the Dunning-Kruger effect ${ }^{[30]}$ that people are not always effective in self-assessing. The Dunning-Kruger effect occurs with incompetent people: precisely because of their incompetence, they lack the metacognitive ability to recognize that their choices and conclusions are sometimes wrong. Less competent healthcare professionals tend to overestimate their performance and skills. As well, highly competent people tend to underestimate themselves. Therefore, we suggest using the PCC self-scan effectively in a dialogue with others, such as colleagues, a team leader, or residents and their relatives, or as a part of a feedback process, correcting the Dunning-Kruger effect by adding perspectives of others.

\subsection{Strengths and limitations}

Whereas the above-mentioned tools developed to measure PCC focus on wards for people with dementia or registered nurses in hospitals, we succeeded in developing a tool for evaluating and improving the quality of PCC continuously for all healthcare professionals in NHs. We included a heterogenous expert panel, including practically trained caregivers, that represented relevant expert domains in all Delphi rounds. We were also successful in involving the perspectives of residents and their relatives.

However, some limitations of the study have to be taken into account. First, we assumed that the tool would not cause extra administrative burden for healthcare organizations, or would cause as little as possible. One can also argue that it is remarkable that nothing about PCC is included in registrations, while this is seen as the gold standard. However, because more administration leads to more time pressure, resulting in less time to provide PCC, we decided to develop a tool that does not put an extra burden on the administration.

Second, we deliberately chose a broad, open-ended question in the first round of the Delphi study. The reason for this was that, to date, no PCC measure has been developed for healthcare professionals. We wanted to provide the experts with the opportunity to come up with outside-the-box ideas, such as feedback mechanisms, reflection methods or learning tools. The downside of such a broad question was that we 
got broad answers and we had to adjust our first plan. Nevertheless, based on this adjusted plan, we were able to answer our research question, with an accessible learning tool as a result.

Furthermore, although all expert domains were represented in all Delphi rounds, participants with practical expertise (i.e., healthcare professionals in NHs), were slightly underrepresented. This can be explained by the outbreak of COVID-19 during this Delphi study. Yet we reached the minimum number of five each round, what we had assumed beforehand, and every voice was heard. Therefore, we argue that the PCC self-scan is suitable for daily practice of all healthcare professionals in NHs.

In addition, the number of residents and relatives interviewed about the PCC self-scan was small. Because of COVID-19, we had to do the interviews by telephone. This form of communication was suboptimal for this target group, and may have caused a lack of clarity regarding the aim and content of the PCC self-scan. Face-to-face interviews would possibly have provided more opportunity to clarify and answer any questions, as we could have shown the PCC self-scan and register the personal (non-verbal) reactions better.

\subsection{Recommendations for future research}

We recommend further research on how healthcare professionals that use the PCC self-scan have a dialogue about their PCC skills, and with whom. This will be part of a follow-up study. Additionally, we suggest a continuing validation of the PCC self-scan among healthcare professionals in NHs, particularly among practically trained caregivers, and a study of to whom and in what context the PCC self-scan is most of help to evaluate and improve PCC. We further suggest validation of the scale dimensionality, construct and content. As the PCC self-scan is a part of a larger project, it is currently being tested among student healthcare professionals as part of two learning programs regarding PCC. We are investigating whether and/or where the PCC self-scan can be useful in care education.

\section{Conclusions}

In this study, we developed an accessible self-report learning tool for healthcare professionals in NHs. A heterogeneous panel, and also residents and their relatives provided their expertise from different perspectives, which ensures broad support for the instrument. The tool helps to raise awareness about PCC-skills individually, and can be used in dialogue with others, to reflect on PCC-skills and learn from the dialogue. The tool contributes to the literature and nursing practice, by making it possible to personally evaluate aspects of PCC by all healthcare professionals in NHs, including practically trained caregivers, to learn from the evaluation and improve the quality of their individual PCC-giving skills.

\section{FUNDING}

The research is financed by the Netherlands Organisation for Health Research and Development (ZonMw) [grant number 516022521, 2019].

\section{ACKNOWLEDgements}

The authors wish to thank all participants in the study for their time and willingness to express their opinions and share their knowledge.

\section{CONFLicts OF INTEREST Disclosure}

No conflict of interest has been declared by the authors.

\section{REFERENCES}

[1] Koren MJ. Person-centered care for nursing home residents: the culture-change movement. Health affairs (Project Hope). 2010; 29(2): 312-7. PMid:20056692 https ://doi .org/10.1377/hlth aff. 2009.0966

[2] Nolan MR, Davies S, Brown J, et al. Beyond 'person-centred' care: a new vision for gerontological nursing. Journal of Clinical Nursing. 2004; 13: 45-53. PMid:15028039 https://doi.org/10.1111/j. 1365-2702.2004.00926.x

[3] Konetzka RT. The Challenges of Improving Nursing Home Quality. JAMA Network Open. 2020; 3(1): e1920231. PMid:31995209 https://doi.org/10.1001/jamanetworkopen. 2019.20231

[4] WHO. WHO global strategy on people-centred and integrated health services : interim report. Geneva: WHO Document production Services; 2015.

[5] McCormack B, McCance T. Person-Centred Practice in Nursing and Health Care : Theory and Practice. Newark: John Wiley \& Sons Ltd.;
2017.

[6] Health Foundation (Great Britain). Person-centred care made simple : what everyone should know about person-centred care. London: The Health Foundation, 2016.

[7] de Silva D. Helping measure person-centred care : a review of evidence about commonly used approaches and tools used to help measure person-centred care. London: Health Foundation; 2014.

[8] Edvardsson D, Innes A. Measuring Person-centered Care: A Critical Comparative Review of Published Tools. The Gerontologist. 2010; 50(6): 834-46. PMid:20566834 https://doi.org/10.1093/ge ront/gnq047

[9] Santana MJ, Ahmed S, Lorenzetti D, et al. Measuring patient-centred system performance: a scoping review of patient-centred care quality indicators. BMJ Open. 2019; 9(1): e023596. PMid:30617101 https ://doi .org/10.1136/bmjopen-2018-023596

[10] Wilberforce M, Challis D, Davies L, et al. Person-centredness in the care of older adults: a systematic review of questionnaire-based scales 
and their measurement properties. BMC Geriatrics. 2016; 16(1). PMid:26951641 https://doi.org/10.1186/s12877-016-022 $9-\mathrm{y}$

[11] Edvardsson D, Fetherstonhaugh D, Nay R, et al. Development and initial testing of the Person-centered Care Assessment Tool (P-CAT). International Psychogeriatrics. 2010; 22(1): 101-8. PMid:19631005 https://doi.org/10.1017/S1041610209990688

[12] Hwang HL, Tu CT, Chen S, et al. Caring behaviors perceived by elderly residents of long-term care facilities: scale development and psychometric assessment. International Journal of Nursing Studies. 2012; 49(2): 183-90. PMid:21945115 https://doi.org/10.101 6/j.ijnurstu.2011.08.013

[13] Mattanja T, Sjenny W, Rudolf BK, et al. Measuring client experiences in long-term care in the Netherlands: a pilot study with the Consumer Quality Index Long-term Care. BMC Health Services Research [Internet]. 2010; 10(1): 95. PMid:20384989 https : //doi.org/10.1186/1472-6963-10-95

[14] Klakovich MDDRNCBC, dela Cruz FADRNF. Validating the Interpersonal Communication Assessment Scale. Journal of Professional Nursing. 2006; 22(1): 60-7. PMid:16459290 https://doi.org/ $10.1016 / j$. profnurs . 2005.12.005

[15] Medvene L, Grosch K, Swink N. Interpersonal complexity: a cognitive component of person-centered care. The Gerontologist. 2006; 46(2): 220-6. PMid:16581886 https : //doi .org/10.1093/gero $\mathrm{nt} / 46.2 .220$

[16] Ekman N, Taft C, Moons P, et al. A state-of-the-art review of direct observation tools for assessing competency in person-centred care. International Journal of Nursing Studies. 2020; 109: 103634. PMid:32531569 https://doi.org/10.1016/j.ijnurstu. 202 0.103634

[17] Edvardsson D, Sjogren K, Lindkvist M, et al. Person-centred climate questionnaire (PCQ-S): establishing reliability and cut-off scores in residential aged care. Journal of Nursing Management. 2015; 23(3): 315-23. PMid:23879558 https://doi.org/10.1111/jonm.121 32

[18] Munyisia EN, Yu P, Hailey D. How nursing staff spend their time on activities in a nursing home: an observational study. Journal of Advanced Nursing. 2011; 67(9). PMid:21466577 https://doi.or $\mathrm{g} / 10.1111 / \mathrm{j} .1365-2648.2011 .05633 . \mathrm{x}$

[19] Thomson MS, Gruneir A, Lee M, et al. Nursing Time Devoted to Medication Administration in Long-Term Care: Clinical, Safety, and Resource Implications. Journal of the American Geriatrics Society. 2009; 57(2): 266-72. PMid:19170782 https ://doi .org/10.111 $1 / j .1532-5415.2008 .02101 . x$

[20] Walent RJ, Kayser-Jones J. Having a voice and being heard: nursing home residents and in-house advocacy. Journal of Gerontological Nursing. 2008; 34(11): 34-42. PMid:19024428 https: //doi.org/10.3928/00989134-20081101-10

[21] Mitchell P, Koch T. An attempt to give nursing home residents a voice in the quality improvement process: the challenge of frailty. Journal of Clinical Nursing. 1997; 6(6): 453-61. https : //doi .or $\mathrm{g} / 10.1111 / \mathrm{j} .1365-2702.1997 . t b 00342 \cdot \mathrm{x}$
[22] Andersson As, Frank C, Willman AML, et al. Factors contributing to serious adverse events in nursing homes. Journal of Clinical Nursing. 2018; 27(1-2): e354-e62. PMid:28618102 https: //doi.org/10.1111/jocn.13914

[23] Baughman RA, Smith KE. Labor mobility of the direct care workforce: Implications for the provision of long-term care. Health Economics. 2012; 21(12): 1402-15. PMid:22025403 https ://doi . or g/10.1002/hec. 1798

[24] Organisation for Economic Cooperation \& Development. A good life in old age? : monitoring and improving quality in long-term care. Paris: OECD/European Commission; 2013. Available from: http://ec.europa.eu/s ocial/BlobServlet?docId=10292\&langId=en https : //doi . org/10.1787/9789264194564-en

[25] Royal Commission into Aged Care Q, Safety. Research Paper 01 - How Australian Residential Aged Care Staffing Levels Compare with International and National Benchmarks. Adeliade, South Australia: Royal Commission into Aged Care Quality and Safety; 2019. Available from: https://nla.gov.au/nla.obj-2924408487https://nla. gov.au/nla.obj-2924408487-thttps://agedcare.royal commission.gov.au/publications/research-paper-1-h ow-australian-residential-aged-care-staffing-level s-compare-international-and-national-benchmarks

[26] The Netherlands Organisation for Health Research and Development (ZonMw). Op weg naar mensgerichte verpleeghuiszorg: scholing als brug tussen wetenschap en praktijk [website]. https://www.zonmw.nl/nl/onderzoek-resultaten/kwal iteit-van-zorg/programmas/project-detail/kwalitei t-van-zorg-ondersteuning-kwaliteitsinstituut/op-w eg-naar-mensgerichte-verpleeghuiszorg-scholing-a ls-brug-tussen-wetenschap-en-praktijk/:ZonMw ; 2019 [updated January 2022; cited 2022 20-1-2022]. Available from: https://www .zonmw.nl/nl/onderzoek-resultaten/kwal iteit-van-zorg/programmas/project-detail/kwalitei t-van-zorg-ondersteuning-kwaliteitsinstituut/op-w eg-naar-mensgerichte-verpleeghuiszorg-scholing-als -brug-tussen-wetenschap-en-praktijk/

[27] Hsu CC, Sandford AB. The Delphi Technique: Making Sense of Consensus. Practical Assessment, Research \& Evaluation. 2007; 12(10): $1-8$.

[28] Slater P, McCance T, McCormack B. The development and testing of the Person-centred Practice Inventory - Staff (PCPI-S). International journal for quality in health care: journal of the International Society for Quality in Health Care. 2017; 29(4): 541-7. PMid:28586441 https://doi.org/10.1093/intqhc/mzx066

[29] Muller-Schoof IJM, Verbiest MEA, Stoop A, et al. How do practically trained (student) caregivers in nursing homes learn? A scoping review. Journal of Nursing Education and Practice. 2022; 12(1): 25-33. https://doi.org/10.5430/jnep.v12n1p25

[30] Kruger J, Dunning D. Unskilled and unaware of it: how difficulties in recognizing one's own incompetence lead to inflated self-assessments. Journal of Personality and Social Psychology. 1999; 77(6): 1121-34. https://doi.org/10.1037/0022-3514.77.6.1121 